\title{
Punitive parenting and delinquency: The mediating role of short-term mindsets
}

\author{
van Gelder, J-L ; Averdijk, M ; Ribeaud, Denis ; Eisner, M
}

DOI: https://doi.org/10.1093/bjc/azx042

Posted at the Zurich Open Repository and Archive, University of Zurich ZORA URL: https://doi.org/10.5167/uzh-166463

Journal Article

Accepted Version

Originally published at:

van Gelder, J-L; Averdijk, M; Ribeaud, Denis; Eisner, M (2018). Punitive parenting and delinquency: The mediating role of short-term mindsets. British Journal of Criminology, 58(3):644-666.

DOI: https://doi.org/10.1093/bjc/azx042 
Punitive parenting and delinquency: The mediating role of short-term mindsets

Jean-Louis van Gelder ${ }^{1}$, Margit Averdijk ${ }^{2}$, Denis Ribeaud ${ }^{2}$, and Manuel Eisner ${ }^{3}$

${ }^{1}$ Netherlands Institute for the Study of Crime and Law Enforcement

${ }^{2}$ Jacobs Center for Productive Youth Development, University of Zurich

${ }^{3}$ Institute of Criminology/Violence Research Center, University of Cambridge 
A wealth of research has revealed robust associations between harsh and inconsistent parental discipline practices and subsequent adolescent delinquency and anti-social behavior (e.g., Hoeve et al. 2009; Patterson 1982; Ribeaud and Eisner 2010). However, in spite of being well documented, theoretical explanations accounting for this link that are also backed up by empirical support are scarce (Gershoff 2002; Simons et al. 2007). Drawing from life history theory and developmental psychology, we theorize that short-term mindsets mediate the relation between parental discipline practices and delinquency. That is, harsh and inconsistent discipline induce an orientation towards the here-and-now rather than contemplating the future, which, in turn, affects delinquency.

We test this assumption distinguishing two types of parental discipline practices, corporal and inconsistent punishment. Although parental punishment encompasses various disciplinary practices (e.g., yelling, spanking, time-outs, e.g., Horn et al., 2004), we focused on corporal and inconsistent punishment, because they map onto two main characteristics of the social environment, namely harshness and unpredictability, which have been shown by theorists to be fundamental in shaping behavioral strategies (e.g., Ellis et al. 2009, 2012; Kruger, Reischl, and Zimmerman 2008). Specifically, harsh and unpredictable environments create a preference for immediate over delayed rewards while also triggering impulsive reactions in order to respond quickly to threats and opportunities when they present themselves (Frankenhuis et al. 2015). As parents provide a window through which their children assess the nature and challenges of the wider environments in which they live (Simpson et al. 2012), we posit that the harshness and unpredictability of parental discipline reflect fundamental dimensions of environmental harshness and unpredictability. Additionally, in line with emerging insights attesting to the multi-dimensionality of presentoriented mindsets (see Nagin and Pogarsky 2004; Steinberg et al. 2009), we operationalize this concept in two different ways, namely impulsivity and (low) future orientation, reflecting 
the inability to consider the delayed consequences of one's actions versus the (un)willingness to do so.

Parental discipline practices: Corporal and inconsistent punishment

The relation between parental discipline practices and antisocial behavior has been the subject of scholarly interest for at least half a century. Various classic longitudinal studies have found that harsh and inconsistent punishment are associated with increased delinquency in offspring. Among the first, Glueck and Glueck (1957) found that inconsistent and threatening punishment practices, along with poor supervision and underdeveloped emotional ties, predicted later delinquency among boys from low-income neighborhoods in Boston. McCord (1979) linked childhood case records from a prevention program to court records of the same individuals thirty years later and found that parental aggression during childhood significantly predicted later convictions for crimes against persons (but not property crimes). Few studies have failed to provide supportive evidence for the association between parental discipline practices and delinquency (Gershoff 2002; Hoeve et al. 2009). In fact, Haapasalo and Pokela (1999: 108) concluded in their review that parental punitiveness is "the most frequently reported family precursor of antisocial behavior" in studies on the family antecedents of problem behavior.

It is worth noting that claims about the harmfulness of parental discipline practices vary dramatically across time and culture (e.g., Sangawi et al., 2015). For example, in recent years, the conceptualization of physical punishment has shifted from acceptable and appropriate to potentially harmful (Durrant, 2008). Regarding cross-cultural variety, there have been hypotheses claiming that physical punishment may not lead to maladjustment in cultures where it is viewed as an expression of love and caring. However, extant research 
indicates consistent links between physical punishment by parents and child externalizing behavior across cultures (Durrant, 2008).

Various studies have differentiated harsh or corporal punishment (e.g., rough handling, spanking, beating) from inconsistent punishment (i.e., unpredictable parental discipline practices). They have found that both are related to later problem behaviors (Patterson 1982; West and Farrington 1973). More specifically, inconsistent parenting predicts aggression and delinquency over and above corporal punishment (e.g., Agnew 1983; Glueck and Glueck 1957).

In spite of robust findings linking punitive practices to subsequent problem behavior, the mechanism explaining the link is unclear (e.g., Gershoff 2002). As Simons et al. (2007: 483) observed, while established perspectives such as self-control theory (Gottfredson and Hirschi 1990) and general strain theory (Agnew 1992) have attempted to theoretically account for the association between parenting quality and delinquency, few studies have empirically investigated mediating effects. Of those that did, a handful have shown that self-control explains part of the relation between parental control and antisocial behavior: increased monitoring and consistent discipline increase self-control, which in turn has a dampening effect on delinquency (e.g., Burt, Simons and Simons 2006; Hay 2001; Simons et al. 2007). Other perspectives that have argued that parental discipline practices trigger feelings of anger and frustration in children, which in turn may result in delinquency, such as general strain theory (Agnew 1992, 2001), have received limited support (Brezina 1998; Broidy 2001; Simons et al. 2007).

In the present study, drawing from life history theory, we provide an alternative explanation for the nexus between parenting and delinquency that extends the current perspectives. We argue that it is, at least in part, explained by the fact that parental discipline 
practices, specifically harsh and unpredictable punishment, change individuals' temporal orientation.

Varieties of shortsightedness: Ability versus willingness to consider the future

Several individual dispositions that revolve around short-term mindsets are related to delinquency. Of these, self-control, defined as the ability to consider the longer-term consequences of one's actions (Gottfredson and Hirschi 1990), has been the commanding approach among criminologists. However, associated constructs such as impulsivity, inhibition, time perspective, consideration of future consequences, future orientation, conscientiousness, sensation seeking, delayed gratification, and vividness of the future self also incorporate shortsightedness in one way or another and also predict delinquency (e.g., Modecki 2008; Nagin and Pogarsky 2003; Van Gelder et al. 2015).

In spite of their convergence in terms of a shared emphasis on temporal orientation, they differ on other dimensions. One such dimension regards the extent to which they reflect the willingness versus the ability to consider future consequences. Some constructs, such as future orientation, are more reflective of the former. Impulsivity is more indicative of the latter (Mamayek, Paternoster and Loughran 2016; Nagin and Pogarsky 2004). Although regularly conflated, e.g., in self-control, there are good reasons to differentiate between the two as they refer to distinct concepts that may operate on delinquency through different pathways (Del Giudice 2015; Steinberg et al. 2009). Accordingly, in this study we include a measure reflecting the inability to consider future consequences, namely impulsivity, and a measure more reflective of the tendency to deliberately (de)value the future, namely future orientation. Note that both constructs can also be further disaggregated into more specific types of temporal orientation or shortsightedness (Nagin and Pogarsky 2004). 
A second dimension on which the constructs may differ regards their stability. Whereas self-control theory posits a rather strict stability assumption arguing that it is acquired early in life with individual differences persisting over the life-course (Gottfredson and Hirschi 1990), recent research indicates that self-control is only moderately stable (Burt, Sweeten and Simons 2014; Hay and Forrest 2006; Vazsonyi, Mikuška \& Kelley 2017). Moreover, because self-control conflates different types of shortsightedness, differences in the development of its constituent traits may have remained obscured (Burt, Sweeten and Simons 2014; Diamond, Morris, and Piquero 2015).

In support of this idea, developmental researchers have argued that future orientation and impulse control may not only have different neural underpinnings but also may develop along different maturational timetables (Steinberg et al. 2009). This begs the question what, if any, other factors other than neural development, early childhood socialization and maturation, influence shortsightedness. In line with recent insights from life history theorists, we argue that shortsightedness shows phenotypic plasticity, develops partly in response to environmental characteristics and remains susceptible to external factors also after the childhood years.

Mediating mechanisms: Short-term mindsets from a life history perspective The possibility that short-term mindsets explain the relation between harsh and inconsistent punishment and delinquency resonates with life history perspectives. Rather than being fixed at birth or crystallizing during early childhood, these models posit that an individual's development and cognitive competencies continuously adapt to environmental stressors 
(Mittal et al. 2015). ${ }^{1}$ Individuals' experiences with the environment are used to form beliefs and generate behavioral strategies to deal with it. A tendency towards adopting a here-andnow orientation in the face of adversity, we argue, may be one such adaptation.

Two environmental dimensions are fundamental in shaping behavioral and cognitive human development: harshness and unpredictability (Mittal et al. 2015). Harshness refers to increased levels of morbidity and mortality that are beyond an individual's control, such as regularly experiencing or witnessing violence, or abusive or neglectful parenting (Ellis et al. 2009). Unpredictability refers to variation in the mean level of harshness across time and space, i.e., is a function of the level of unpredictable variation ("stochasticity") in environmental risk (Brumbach et al. 2009).

Individuals who are surrounded by relatively harsh and unpredictable environments, e.g., rough neighborhoods or violent family conflicts, are likely to develop more presentoriented strategies to capitalize on the (possibly) fleeting opportunities these environments offer (Frankenhuis et al. 2016). Behavioral strategies that are the result of such environments are manifested in increased vigilance to detect threats and opportunities, impulsive reactions with little deliberation in order to respond quickly, and steep future discounting to motivate the capture of immediate benefits (Frankenhuis et al., 2016: 77). That is, exposure to unpredictable conditions may orient individuals toward immediate payoffs at the expense of delayed rewards as future rewards are less likely to be cashed in (Frankenhuis et al. 2016).

The effects of harsh and unpredictable environments are especially large during childhood and adolescence (Simpson et al. 2012). As Ross and Hill (2002) explain, childhood

\footnotetext{
${ }^{1}$ Note that when referring to the adoption of a present-orientation as 'adaptive' what is referred to is biological fitness, not health or wellbeing (Frankenhuis et al. 2016). As stated by Loewenstein (1996: 275), the 'goal' of evolution is reproduction, not happiness.
} 
unpredictability contributes to a belief that people are unpredictable and the world is chaotic which, in turn, orients individuals toward the "here and now" and increases risk-taking. Development of such "unpredictability schema" may be an important mediating mechanism through which exposures to unpredictability shift individuals toward faster life history strategies.

In sum, life history strategies correlate with certain clusters of psychosocial traits, which facilitate the successful enactment of each strategy (Simpson et al. 2012). As fast life history strategies promote a focus on current rewards, discounting the future, and risk taking, individual differences in temporal orientation overlap with the fast-slow continuum of life history variation (Del Giudice 2015). Thus, harsh and uncertain environments should favor short-term mindsets over long-term planning.

\section{Empirical support}

Recent longitudinal studies have found that environmental harshness and unpredictability exert unique but similar effects on behavior. For example, Simpson et al. (2012), using the Minnesota Longitudinal Study of Risk and Adaptation, examined how exposure to harsh (operationalized by low SES) versus unpredictable environments (indexed as changes in mothers' employment status, residence, and cohabitation) during childhood predicted risky behavior in early adulthood. Individuals exposed to more unpredictable environments later displayed a faster life history strategy as indicated by having more sexual partners, having sex at an earlier age (for males), and more aggression and delinquent behaviors. Exposure to either harsh environments or experiencing unpredictability later in childhood (ages 6-16) did not significantly predict these outcomes at age 23 .

In contrast, Brumbach et al. (2009) using Add Health data found that both unpredictability (measured by frequent changes or ongoing inconsistency in several 
dimensions of childhood environments) and harshness in adolescence (operationalized as exposure to violence from conspecifics) independently predicted the adoption of faster life history strategies, such as greater deviance, in young adulthood, suggesting that unpredictable and harsh environments experienced beyond early childhood affect behavioral adaptations too.

What previous studies have not directly addressed, however, is the psychological mechanism explaining the association between unpredictability and harshness and problem behavior. In the present study, we test whether short-term mindsets form the mediation link. Although, to our knowledge, no studies have directly tested this mediation hypothesis, there is some empirical evidence that suggests it is plausible. Several studies have, for example, associated problem behavior with cognitive perceptions of stability and predictability of the future (e.g., Caldwell et al. 2006). For example, Kruger et al. (2008) found that negative aspects of the developmental social environment (unpredictability in personal safety and resource retention) were directly related to present-orientation, which in turn related to both interpersonal aggression and illicit exploitation of resources. Positive aspects of the environment (perceptions of physical safety, positive socialization, and the helpfulness of others), conversely, were related to future orientation.

Brezina, Terkin and Topalli (2009) found that the anticipation of an early death, a measure of futurelessness, led youth to engage in crime. Accounts by offenders point to several mediators including a present-time orientation, perceived salience of immediate benefits, and a disregard for the future consequences of behavior, that may result from the anticipation of early death (Brezina, Terkin and Topalli, 2009). Two additional mechanisms that may link anticipated early death to crime, and that were implicit in the offender interviews were the development of an "unpredictability schema"-a pervasive belief that the world is a chaotic place, and a lack of investment in conventional pursuits associated with 
delayed benefits, such as school or legitimate work. In line with Brezina et al. (2009), Wilson and Daly (1997) found that homicide rates in Chicago were predicted by low neighborhood life expectancy, with mortality effects of homicide removed, and neighborhood income inequality. The authors argued that risky behaviors such as committing homicide are a result of future discounting.

Although informative, no studies to date have tested the link between adverse environments and delinquency via short-term mindsets. The present study intends to fill this gap. The distinction between corporal and inconsistent punishment is particularly interesting because it maps directly onto the division between harsh and unpredictable environments. A child growing up in a family environment characterized by regular physical punishment grows up in a context with the characteristics of a harsh environment. In a similar vein, inconsistent punishment practices reflect the socio-spatial variation characteristic of unpredictable environments.

The present study

We assess the influence of corporal and inconsistent punishment on delinquency, theorizing that experiencing these types of parental discipline practices increases people's shortsightedness, which, in turn, results in delinquency. We distinguish between two types of short-term mindsets, i.e., the ability to consider the future consequences of one's behavior, measured by impulsivity, and the willingness to do so, measured by future orientation. In line with earlier findings from both the developmental psychology literature and life history theory, we predict that corporal and inconsistent punishment account for unique variance in delinquency but we do not advance differential predictions for these variables. The hypothesized model is presented in Figure 1. 
Figure 1 about here

We test our hypothesis using longitudinal data from the Zurich Project on the Social Development from Childhood into Adulthood controlling for gender, socioeconomic status (SES), and ethnicity. Importantly, we also control for earlier levels of shortsightedness, delinquency, and child temper as a measure of trait anger as this latter factor may affect the causal relation between parenting, shortsightedness and delinquency. That is, parenting may not only be a cause of child behavior, but also a reaction to it (Jackson and Beaver 2015). In the Discussion, we review our results in the light of existing criminological theory.

\section{Method}

\section{Participants}

Data were drawn from the combined longitudinal and intervention study, the Zurich Project on the Social Development from Childhood into Adulthood (z-proso) (Eisner, Malti and Ribeaud 2011). To minimize possible contamination or spillover effects between the interventions' treatment conditions, sampling was based on a cluster randomized approach with schools as randomization units. All 90 public primary schools in the city of Zurich, Switzerland, were blocked by enrollment size and socio-economic background of the catchment area. Subsequently, a stratified sample of 56 schools was drawn, comprising 1,675 first graders (age 7). Schools in disadvantaged school districts were slightly overrepresented in the sample. The implemented interventions did not affect aggression, delinquency or other 
antisocial outcomes (Averdijk, Zirk-Sadowski, Ribeaud and Eisner 2016; Malti, Ribeaud and Eisner 2011). The sample was $52 \%$ male and ethnically diverse. In $46 \%$ of all cases, both parents were born outside of Switzerland.

The data collection started in 2004 when the children were 7 years old. We used data from the three most recent waves (five, six and seven) because the measures of interest were included in these waves. At wave 5, when the youths' mean age was 13.7 years $(S D=0.37)$, $82 \%$ of the children from the original target sample participated. At wave 6 , when the mean age was 15.4 years $(S D=0.36)$, participation from the original target sample was $86 \%$. At wave 7 , when the mean age was 17.4 years $(S D=.37), 78 \%$ of the youths from the original target sample were still included. In line with local data protection regulations, passive parental consent was obtained for each participant at wave 5 and 6 , and active informed consent was obtained from each participant at wave 5 or 6 , and at wave 7 . The youths completed a paper and pencil questionnaire, the latter in a classroom setting. The youths' assessments took place during leisure time and they received a participation incentive worth the equivalent of 30,50, and 60 US\$ at each respective wave.

\section{Measures}

Delinquency. At waves 5 and 7, the past-year prevalence of 14 types of delinquency was self-reported by the youths. Items included stealing at home, stealing at school, shoplifting something worth more than about 50 dollars, shoplifting something worth less than about 50 dollars, vehicle theft, driving without a license, burglary and stealing from a car, drug dealing, graffitying, vandalism, carrying a weapon, threatening and extortion, 
robbery, and assault. ${ }^{2}$ The scale was adapted from Wetzels et al. (2001). All items were coded into a dichotomy, with 0 ('did not commit the offence') and 1 ('did commit the offence'), on the basis of which a variety scale was computed (Bendixen et al. 2003). Variety scales have been termed 'the preferred criminal offending scale' because they display high reliability and validity, are less skewed than frequency measures, and are not compromised by highfrequency crime-types of low seriousness (Sweeten 2012).

Future orientation. At waves 5 and 6, three items measured future orientation towards school ("When I grow up I want to have an interesting job, and I'm doing everything now to work towards that goal", "I try hard at school to have a good job later in life" and "Doing well at school is important to me"). Answer categories were recorded on a 4-point Likert scale from 1 "false" to 4 “true". Because Cronbach's alpha is biased for scales with a low number of items (Eisinga, Te Grotenhuis, and Pelzer 2013), the mean inter-item correlation has been found to be a more appropriate measure for assessing scale reliability (Briggs and Cheek 1986; Clark and Watson 1995). The inter-item correlation for future orientation was satisfactory with $r=.473$ at wave 5 and $r=.524$ at wave 6 . These measures primarily referred to future school orientation and school achievement in relation to later life success. Given the age of our sample, this was considered to be the most appropriate measure of future orientation.

Impulsivity. At waves 5 and 6, two items from the self-control scale by Grasmick, Tittle, Bursik, and Arneklev (1993) (see Ribeaud and Eisner 2006) assessed impulsivity (“I

\footnotetext{
${ }^{2}$ The main analyses were also performed using a more encompassing deviance scale of 19 items, which included all items included in the 14-item scale plus truancy, cheating at school, running away from home, illegal uploading and downloading and fare dodging. Results were similar.
} 
often act on the spur of the moment without stopping to think" and "I often do whatever brings me pleasure here and now, even at the cost of some distant goal"). Answer categories on a 4-point Likert scale ranged from 1 "false" to 4 "true". The inter-item correlation between the impulsivity items was satisfactory with $r=.273$ at wave 5 and $r=.275$ at wave 6 .

Parental discipline practices. We included data from an adapted youth self-report version of the Alabama Parenting Questionnaire (APQ; Shelton, Frick and Wootton 1996; Topçuoğlu, Eisner and Ribeaud 2014) collected at waves 5 and 6. It measured parenting practices in several domains (parental involvement, positive parenting, poor monitoring/supervision, authoritarian parenting, inconsistent discipline and corporal punishment) on the basis of face validity. It also included additional items for specific types of punishment to avoid negative bias (e.g., taking away privileges). The items that focus on disciplinary practices followed a separate introduction, asking respondents what their parents do when the youths do something wrong. Although the majority of studies that have assessed the psychometric properties of the APQ have focused on parent reports, there are studies that have examined the youth reports. These studies, conducted across different countries and in different languages, have supported a 2- to 5-factor solution (e.g., Molinuevo et al., 2011). For example, a Spanish study supported a 4-factor solution after removal of the corporal punishment scale (Escribano et al., 2013), whereas the results of an Italian study suggested two factors (Esposito et al., 2016). Researchers in Germany found support for a 5-factor solution, but had to remove several items, for example for inconsistent parenting (Essau et al., 2006). An exploratory factor analysis of the parental discipline items in our study revealed a 4-item-scale for corporal punishment ("Your parents slap you", "Your parents spank you with their hand", "Your parents pull your hair or ears" and "Your parents hit you with a belt, staff, or other object") and a 3-item scale for inconsistent punishment ("Your parents threaten to punish you but subsequently do nothing", "You talk your parents out of punishing you when 
you have done something wrong" and "Your parents let you out of a punishment early, or reduce the punishment (e.g., you are allowed to watch TV or go out earlier than originally said)") . Answer categories on a 4-point Likert scale ranged from 1 "never" to 4 "often/always". For corporal punishment, the mean inter-item correlation was $r=.439$ at wave 5 and $r=.429$ at wave 6 . For the inconsistent punishment items, the mean inter-item correlation was $r=.224$ at wave 5 and $r=.263$ at wave 6 .

Control variables. We included available prior measures of delinquency, future school orientation and impulsivity. In accordance with the Cambridge Quality Checklists (Murray, Farrington, and Eisner 2009), wave 6 control variables were not included because control variables measured in the same wave as the predictors might act as mediating mechanisms. We therefore measured all control variables at wave 5. We also controlled for gender ("0" for females and " 1 " for males), ethnicity (with " 0 " signifying at least one Swiss parent and "1" two non-Swiss parents), and socio-economic status (SES). ${ }^{3}$ The latter was based on the caregiver's current profession (Elias and Birch 1994) and transformed into an International Occupational Status (ISEI) score (Ganzeboom et al. 1992). The final SES score was based on the highest ISEI score of the two caregivers.

Table 1 about here

\footnotetext{
${ }^{3}$ We note that prior studies (e.g., Simpson et al., 2012) have used SES as a measure of harshness. Given the focus of the present study, it was appropriate to include SES as a control variable to avoid confounding effects.
} 
Results

We included all youths who had participated in each of the three waves $(N=1,197 ; 71.3 \%)$. Missing data occurred due to attrition and item-level non-response. For those youths who participated in all three waves, $1 \%$ of all data-points was missing. We used robust fullinformation maximum likelihood estimation (FIML) to handle the missing data (Enders and Bandalos 2001; Larsen 2011).

\section{Correlations}

Most of the correlations between the main variables were significant and in the expected direction (Table 1). Corporal and inconsistent punishment were related to increased impulsivity, increased volatile temper, and delinquency, whereas corporal (but not inconsistent) punishment was related to decreased future orientation. In line with our theoretical model, corporal and inconsistent punishment were not correlated and hence can be considered to be independent factors. Furthermore, lower future orientation, higher impulsivity, and higher volatile temper were all related to higher delinquency. Finally, all the same variables across the different waves were strongly correlated.

Table 2 about here

\section{Mediation model}

Next, we estimated a longitudinal path model in Mplus (Muthén and Muthén 1998-2015) to test our mediation hypothesis. We used maximum likelihood estimation with robust standard 
errors to account for deviations from multivariate non-normality. We also corrected for clustering within classes. ${ }^{4}$ Because delinquency is measured on a count scale, we used a negative binomial model for this outcome variable (Hilbe 2011). Because Mplus does not provide absolute fit statistics for our model, we estimated a linear path regression model in Stata (StataCorp, College Station, TX) in order to provide a general idea of model fit. The results, obtained using maximum likelihood without robust standard errors, were similar to those reported below with excellent fit statistics: standardized root mean square residual $(\mathrm{SRMR})=.01 ;$ Tucker Lewis index $(\mathrm{TLI})=.97 ;$ comparative fit index $(\mathrm{CFI})=.99 ;$ root mean square error of approximation $(\mathrm{RMSEA})=.03(\mathrm{Hu}$ and Bentler 1999). The results show that both types of parental discipline practices (corporal punishment and inconsistent punishment) predicted impulsivity (Table 2). The effect of inconsistent (but not corporal) punishment on future orientation was significant at the $p<.10$ level only. Furthermore, in line with expectations, high levels of future orientation reduced delinquency, whereas high levels of impulsivity increased it. After inclusion of the mediating variables, the direct effect of corporal and inconsistent punishment on delinquency remained significant (although for the latter it was only marginally significant at $p<.10$ ). The tests of the mediating mechanisms are reported under "Indirect effects" in Table 2. Impulsivity mediated the effects of corporal and inconsistent punishment on delinquency. Future orientation also mediated the effect of corporal punishment on delinquency, but only at the $p<.10$ level.

\section{Robustness checks}

\footnotetext{
${ }^{4}$ For those youths who no longer attended school and thus could not be assigned a class code, we created individual codes.
} 
In order to test the robustness of these results, we performed several additional analyses. Included variables not discussed in the Method section are presented in Appendix A.

First, we tested whether the results could be explained by alternative theoretical explanations, in particular by the assumption that the pathway between parental discipline practices and delinquency is mediated by volatile temper, which is a measure of trait anger, as suggested by General Strain Theory (Agnew 1992, 2001). We therefore included a mediation pathway via volatile temper, reported under Model 1 in Table 3a. Corporal and inconsistent punishment were associated with increased youths' volatile temper. However, volatile temper did not predict delinquency and did not mediate the link between parental discipline practices and delinquency. Furthermore, after inclusion of this pathway, the mediation links through shortsightedness remained. In other words, we do not find support for the explanation of the link between parental discipline practices and delinquency offered by General Strain Theory.

Second, we tested whether the hypothesized links were similar for violent and property offending. The results are shown under Model 2 and Model 3 respectively. Future orientation and impulsivity predicted both violence and property offenses. Furthermore, there was a significant direct effect of corporal and inconsistent punishment on theft, but not on violence, even after inclusion of the mediator variables. Impulsivity mediated the link between parental discipline practices and both violence and theft, although the link with theft was significant at the $p<.10$ level only.

Third, our temporal measurement scheme was not, strictly speaking, unambiguous because the predictors and mediators were measured at the same time-point. Although future school orientation was a point measure, providing an unambiguous point of reference relative to parental discipline practices (Menard and Elliott 1994), the impulsivity variable referred to past actions and might therefore be confounded with parental discipline practices, which was measured at the same time-point as impulsivity and also referred to past behavior. We 
therefore also tested longer-term links where the predictors were measured one wave prior to the measurement of the mediators. The results are displayed under Model 4 in Table $3 b .{ }^{5}$ They show that inconsistent but not corporal punishment was related to higher impulsivity two years later. Impulsivity, in turn, was, as already determined, related to delinquency. The pathway of inconsistent punishment to delinquency was significantly mediated by impulsivity, even with the longer time lags between the measurements. In sum, these additional analyses lend credibility to the robustness of the results against alternative theoretical explanations and measurements.

Tables $3 \mathrm{a}$ and $3 \mathrm{~b}$ about here

Discussion

This study proposed and tested the hypothesis that the effect of parental discipline practices on delinquency operates in part via short-term mindsets. This assumption was explained in

\footnotetext{
${ }^{5}$ Because we did not measure future orientation at wave 4 , we used W4 impulsivity as a control variable for the regression of W6 future orientation. We did not see this as problematic, because the mediation pathway of W5 parental discipline practices to W7 delinquency through W6 impulsivity is of primary interest here and we therefore focus on these effects in this paragraph (because W6 future orientation, as discussed, is a point measure and therefore already provides an unambiguous point of reference relative to the W6 parental discipline practices variables in the other presented analyses).
} 
terms of life history perspectives that have addressed the relation between adverse environmental circumstances and problem behavior. Using data from the Zurich Project on the Social Development of Children and Youths (z-proso), we distinguished between corporal and inconsistent punishment, which map onto two environmental dimensions that are fundamental in triggering short-term behavioral strategies, i.e., harshness and unpredictability. In line with expectations, we found harsh and inconsistent punishment to operate on subsequent delinquent behavior in part through short-term mindsets, which was operationalized in two different ways, through impulsivity and future orientation, respectively reflecting the inability versus the unwillingness to consider the future consequences of behavior. Moving away from the commanding perspective of shortsightedness in criminology, self-control, we found that impulsivity and future orientation each explained unique variance in delinquency and both to partially mediate the relation between parental discipline practices and delinquency, with impulsivity being the most important mediator.

The idea that shortsightedness mediates the relation between parental discipline practices and delinquency can be brought within the ambit of self-control theory according to which self-control is rooted in parenting practices during childhood. Harsh and inconsistent parental discipline practices, according to this perspective, may prevent the moral internalization of norms and rules by eroding the attachment bond between parent and child. Children who are not emotionally attached to their parents may not internalize their parents' values and those of the larger society, which in turn will result in low self-control, predisposing them toward problem behavior. We believe that our account is more in line with the results for various reasons.

First, we examined two narrower and distinct constructs reflecting shortsightedness, namely the deliberate devaluation of the future versus the inability to do so, which are not separated in self-control (Nagin and Pogarsky 2004), and showed that they both partially 
mediate the relation between parental discipline practices and delinquency. Importantly, impulsivity and future orientation were only weakly correlated which lends credence to the view that they are independent constructs reflecting different types of shortsightedness.

Second, self-control theory assumes differences in self-control to be fixed after childhood. We found, however, that shortsightedness is a more environmentally responsive construct and that parental discipline practices during adolescence affect delinquency via short-term mindsets, even when controlling for prior levels of delinquency. This is in line with a study by Hay and Forrest (2006) who found that the effects of parental socialization continued to affect self-control during adolescence.

Third, and finally, unlike self-control theory, our account offers a relatively detailed account of how parental discipline practices shape shortsightedness. As Burt (2014: 149) observes, for Gottfredson and Hirschi, parenting practices are to ingrain the ability to appreciate that the immediate pleasures from crimes are outweighed by their painful and more distant consequences without offering much detail as to how this should occur. Our model indicates that the reason that parental discipline practices increase the probability that immediate pleasures are enjoyed at the expense of future costs is that corporal and inconsistent punishment reflect harsh and unpredictable environments to which youths adapt by becoming more present oriented.

Our results also extend the proposed pathway between parental discipline practices and delinquency proposed by General Strain Theory (Agnew 1992, 2001). Whereas General Strain Theory assumes that emotions like anger mediate the relation between negative life experiences and delinquency, we were unable to confirm that pathway for parental discipline practices once shortsightedness was included. That is, although parental discipline practices, a measure of negative life experiences, was related to increased volatile temper (our measure for trait anger), the latter was not related to later delinquency. Instead, our data provided 
stronger evidence for the hypothesis that short-term mindsets form the main nexus between parental discipline practices and delinquency. It is, nevertheless, possible that volatile temper increases shortsightedness, and in fact, our data showed that decreased future orientation and increased impulsivity were related to higher volatile temper. Thus, our perspective may extend General Strain Theory by explaining how anger leads to delinquency, namely through increased shortsightedness. This is in line with emotion research which shows that experiencing anger tends to keep one's attention confined to the situation that provoked it and reduces people's ability to consider the long-term consequences of their actions (Averdijk et al. 2016; Loewenstein 1996; Van Gelder 2013).

This study was conducted in Switzerland, where self-reported rates of anti-social and other risk behaviors are average or above compared to other European countries and the U.S. (Craig et al., 2009; Currie et al., 2012; Simons-Morton et al., 2009). The high cultural heterogeneity of our sample may suggest cross-cultural validity of our findings. However, as with other research restricted to a single country, replications in other countries are nonetheless recommended.

In sum, this study showed that short-term mindsets may develop in part as a consequence of environmental stressors. According to the life history theory perspective used, biological makeup and early childhood socialization determine initial levels of shortsightedness, while subsequent development reflects a response to environmental influences. The development of temporal orientation, like other life history traits, is therefore a product of both genetic and environmental influences. In sum, our results are in line with recent findings hinting at the instability of self-control over the life course, but they extend these findings by also explaining what causes this instability.

In spite of these results, this study was prone to limitations. For one thing, although we distinguished between different types of shortsightedness, each of these can be further 
subdivided into sub-types (Nagin and Pogarsky 2004; Sharma, Markon and Clark 2014). Our measure of impulsivity was also suboptimal in the sense that it only consisted of two items. Future research is therefore advised to use more extensive measures and explore different types of shortsightedness. Also, our measure of future orientation was domain-specific, relating to school orientation and achievement in relation to later life success. Given the age of our sample and daily time spent in school we think this was appropriate, yet future research is advised to also incorporate broader measures of future orientation.

Perhaps the most important limitation was that in spite of its longitudinal nature, this study could not conclusively determine causation. To exclude alternative interpretations, parenting practices need to be exogenous to the developing individuals, which they are not (Brumbach et al. 2009). As with other behavioral research, it is possible that adolescents' own behaviors, including genetically influenced personality dispositions, have influenced their exposure to harsh parental treatment. By controlling for a series of variables that may have influenced the relation between parenting and delinquency, such as child temper and prior delinquency, we have attempted to limit these concerns as much as possible.

To further venture into the mechanisms that can explain the relation between harsh and inconsistent parental discipline practices and delinquency, future research could examine possible moderators. Besides mediating pathways, several factors may exacerbate or buffer the impact of negative childhood experiences on delinquency. As most people who have been abused or spanked during childhood do not grow up to be violent or criminal adults this contradicts the idea that corporal punishment necessarily has negative effects (Gershoff 2002). Additional important variables that could be included are, for example, duration, frequency and intensity of the punishment. Furthermore, research could venture into individual dispositions such as personality traits as possible mitigating or exacerbating factors. 
Finally, although we have limited our examination of shortsightedness to the context of parenting, future research could extend it to examine effects of the neighborhood or community to contribute to a more encompassing theory of delinquency. The perspective used in the present study makes it plausible that similar psychological processes that account for the relation between parenting and delinquency also explain neighborhood and context effects. This would address an important gap in the knowledge base as we have virtually no information regarding the cognitive and emotional processes that mediate the impact of community disadvantage, collective efficacy, or community crime on delinquency (Simons et al. 2007).

\section{Conclusions}

Having arrived at the final section of this article, we permit ourselves to speculatively contemplate potential implications of these results. One of the main implications appears to be that crime policy should address factors in the environment that affect shortsightedness. This may appear like stating the obvious but we think that the 'success' of the self-control paradigm in explaining delinquency and its insistence on stability has obscured the fact that shortsightedness is amenable to change also after the assumed formative childhood years, both in a positive and negative way. To start with the latter, policy and behavioral interventions are advised to consider the effect of environmental circumstances, including parenting, that contribute to the adoption of a short-term mindset. By targeting those elements in the developmental environment, important ground can be gained in the way of crime prevention.

On the other hand, rehabilitation and crime prevention programs may benefit from the insights of life history frameworks by investing in interventions that aim to increase people's future orientation. One such example regards recent work by Van Gelder and colleagues 
$(2013,2015)$ who showed that instilling a greater sense of vividness of the future self in adolescents and young adults induced an orientation towards the future and reduced delinquency. The authors used virtual reality technology and social media to acquaint youth with realistic visual renderings of their future self and had them interact with that future self. These experimental studies show that instilling a greater sense of vividness led to reduced delinquency. An intervention study by Oyserman and colleagues (2006) working with the notion of possible future selves combined the induction of a stronger future orientation for youth living in urban and poor neighborhoods with a sense that they can control their own destiny by improving planning skills. This randomized trial resulted in improved behavior and better academic skills.

In sum, programs and interventions actively encouraging adopting a future-orientation in adolescents and young adults, making clear the dangers of adopting a present-oriented mindset and creating less harsh and more predictable developmental environments all hold promise to contribute to decreasing delinquent propensity and reducing criminal conduct. 


\section{References}

Agnew, R. (1983), Physical punishment and delinquency: A research note. Youth and Society, 15, 225.

Agnew, R. (1992). Foundation for a general strain theory of crime and delinquency. Criminology, 30, 47-88.

Agnew, R. (2001). Building on the foundation of general strain theory: Specifying the types of strain most likely to lead to crime and delinquency. Journal of Research in Crime and Delinquency, 38, 319-61.

Attar, B K., Guerra, N. G., \& Tolan, P. H. (1994). Neighborhood disadvantage, stressful life events and adjustments in urban elementary-school children. Journal of Clinical Child Psychology, 23, 391-400.

Averdijk, M., Van Gelder, J. L., Eisner, M. P., \& Ribeaud, D. (2016). Violence begets violence...But how? A decision making perspective on the victim-offender overlap. Criminology, 54, 282-306.

Averdijk, M., Zirk-Sadowski, J., Ribeaud, D., \& Eisner, M. P. (2016). Long-term effects of two childhood psychosocial interventions on adolescent delinquency, substance use, and antisocial behavior: a cluster randomized controlled trial. Journal of Experimental Criminology, 12, 21-47.

Brezina, T. (1998). Adolescent maltreatment and delinquency: The question of intervening processes. Journal of Research in Crime and Delinquency, 35, 71-99.

Brezina, T., Tekin, E. \& Topalli, V. (2009). "Might not be a tomorrow”: A multimethods approach to anticipated early death and youth crime. Criminology, 47, 1091-1129. 
Briggs, S. R., \& Cheek, J. M. (1986). The role of factor analysis in the evaluation of personality scales. Journal of Personality, 54, 106-148.

Broidy, L. (2001). A test of general strain theory. Criminology, 39, 9-33.

Burt, C. H., Simons, R. L., \& Simons, L. G. (2006). A longitudinal test of the effects of parenting and the stability of self-control: Negative evidence for the General Theory of Crime. Criminology, 44, 353-396.

Burt, C. H. (2014). Self-Control and Crime: A Sociological Perspective. In K. Beaver, J.C Barnes, \& B. Boutwell (Eds.), The Nurture versus Biosocial Debate in Criminology pp.143-171. Sage.

Burt, C. H., Sweeten, G. \& Simons, R. L. (2014). Self-control through emerging adulthood: Instability, multidimensionality, and criminological significance. Criminology. 52, $450-487$.

Brumbach, B. H., Figueredo, A. J., \& Ellis, B. J. (2009). Effects of harsh and unpredictable environments in adolescence on development of life history strategies. Human Nature, 20,25-51.

Clark, L. A., \& Watson, D. (1995). Constructing validity: Basic issues in objective scale development. Psychological Assessment, 7, 309-319.

Craig, W., Harel-Fisch, Y., Fogel-Grinvald, H., Dostaler, S., Hetland, J., Simons-Morton, B., et al. (2009). A cross-national profile of bullying and victimization among adolescents in 40 countries. International Journal of Public Health, 54, 216-224.

Currie, C., Zanotti, C., Morgan, A., Currie, D. De Looze, M., Roberts, C., et al. (Eds., 2012). Social determinants of health and well-being among young people. Health Behaviour in School-aged Children (HBSC) study: international report from the 2009/2010 survey. Copenhagen, WHO Regional Office for Europe, 2012 (Health Policy for Children and Adolescents, No. 6). 
Del Giudice, M. (2015). Self-regulation in an evolutionary perspective. In Guido H. E. Gendolla and Mattie Tops (Eds.), Handbook of Biobehavioral Approaches to SelfRegulation. New York: Springer.

Diamond, B., Morris, R. G., \& Piquero, A. R. (2015). Stability in the underlying constructs of self-control. Crime and Delinquency, 63 (3), 235-266.

Durrant, J. E. (2008). Physical punishment, culture, and rights: Current issues for professionals. Journal of Developmental \& Behavioral Pediatrics, 29, 55-66.

Eisinga, R., Grotenhuis, M. T., \& Pelzer, B. (2013). The reliability of a two-item scale: Pearson, Cronbach, or Spearman-Brown? International Journal of Public Health, 58, 637-642.

Eisner, M. P., Malti, T., \& Ribeaud, D. (2011). Large-scale criminological field experiments. In Gadd, D., Karstedt, S., \& Messner, S. (Eds.), Sage handbook of criminological research methods. London: Sage.

Ellis, B. J. (2004). Timing of pubertal maturation in girls: An integrated life history approach. Psychological Bulletin, 130, 920-958.

Ellis, B. J., Del Giudice, M., Dishion, T. J., Figueredo, A. J., Gray, P., Griskevicius, V. \& Wilson, D. S. (2012). The evolutionary basis of risky adolescent behavior: implications for science, policy, and practice. Developmental Psychology, 48, 598-623.

Ellis, B. J., Figueredo, A. J., Brumbach, B. H., \& Schlomer, G. L. (2009). Fundamental dimensions of environmental risk. The impact of harsh versus unpredictable environments on the evolution and development of life history strategies. Human Nature, 20, 204-268.

Enders, C. K., \& Bandalos, D. L. (2001). The relative performance of full information maximum likelihood estimation for missing data in structural equation models. Structural Equation Modeling, 8, 430-457. 
Escribano, S., Aniorte, J., and Orgilés, M. (2013). Factor structure and psychometric properties of the Spanish version of the Alabama Parenting Questionaire (APQ) for children. Psicothema, 25, 324-329.

Esposito, A., Servera, M., Garcia-Banda, G., \& Del Giudice, E. (2016). Factor analysis of the Italian version of the Alabama Parenting Questionnaire in a community sample. Journal of Child and Family Studies, 25, 1208-1217.

Essau, C. A., Sasagawa, S., \& Frick, P. J. (2006). Psychometric properties of the Alabama Parenting Questionnaire. Journal of Child and Family Studies, 15, 597-616.

Figueredo, A. J., Vásquez, G., Brumbach, B. H., Schneider, S. M., Sefcek, J. A., Tal, I. R., Hill, D., Wenner, C. J., \& Jacobs, W. J. (2006). Consilience and life history theory: From genes to brain to reproductive strategy. Developmental Review, 26, 243-275.

Frankenhuis, W. E., Panchanathan, K., \& Nettle, D. (2016). Cognition in harsh and unpredictable environments. Current Opinion in Psychology, 7, 76-80.

Ganzeboom, H. B. G., de Graaf, P. M., \& Treiman, D. J. (1992). A standard international socio-economic index of occupational status. Social Science Research, 21, 1-56.

Gershoff, E. T. (2002). Corporal punishment by parents and associated child behaviors and experiences: a meta-analytic and theoretical review. Psychological Bulletin, 128, 539579.

Glueck, S., \& Glueck. E. (1957). Unraveling Juvenile Delinquency. Cambridge: Harvard University Press.

Gottfredson, M. R., \& Hirschi, T. (1990). A General Theory of Crime. Stanford: Stanford University Press.

Grasmick, H. G., Tittle, C. R., Bursik, R. J., \& Arneklev, B. J. (1993). Testing the core empirical implications of Gottfredson and Hirschi's general theory of crime. Journal of Research in Crime and Delinquency, 30, 5-29. 
Griskevicius, V., Tybur, J. M., Delton, A. W., \& Robertson, T. E. (2011). The influence of mortality and socioeconomic status on risk and delayed rewards: a life history theory approach. Journal of Personality and Social Psychology, 100, 1015-1026.

Hay, C. (2001). Parenting, self-control, and delinquency: A test of self-control theory. Criminology, 39, 707-736.

Hilbe, J. M. (2011). Negative binomial regression. Cambridge: Cambridge University Press.

Hirschi, T., \& M. R. Gottfredson. (1995). Control theory and the life-course perspective. Studies on Crime and Crime Prevention, 4, 131-142.

Hoeve, M., Dubas, J. S., Eichelsheim, V. I., Van der Laan, P., Smeenk, W. \& Gerris, J. R. (2009). The relationship between parenting and delinquency: A meta-analysis. Journal of Abnormal Child Psychology, 37, 749-775.

Horn, I. B., Joseph, J. G., \& Cheng, T. L. (2004). Nonabusive physical punishment and child behavior among African-American children: a systematic review. Journal of the National Medical Association, 96(9), 1162.

Hu, L., \& Bentler, P. M. (1999). Cutoff criteria for fit indexes in covariance structure analysis: Conventional criteria versus new alternatives. Structural Equation Modeling: A Multidisciplinary Journal, 6, 1-55.

Jackson, D. B., \& Beaver, K. M. (2015). A shared pathway of antisocial risk: A path model of parent and child effects. Journal of Criminal Justice, 43(2), 154-163.

Kruger, D. J., Reischl, T., \& Zimmerman, M. A. (2008). Time perspective as a mechanism for functional developmental adaptation. Journal of Social, Evolutionary, and Cultural Psychology, 2, 1-22. 
Larsen, R. (2011). Missing data imputation versus full information maximum likelihood with second-level dependencies. Structural Equation Modeling: A Multidisciplinary Journal, 18, 649-662.

Loewenstein, G. (1996). Out of control: Visceral influences on behavior. Organizational Behavior and Human Decision Processes, 65, 272-292.

Malti, T., Ribeaud, D., \& Eisner, M. P. (2011). The effectiveness of two universal preventive interventions in reducing children's externalizing behavior: a cluster randomized controlled trial. Journal of Clinical Child and Adolescent Psychology, 40, 677-692.

Mamayek, C., Paternoster, R. \& Loughran, T. (2016). Temporal discounting, present orientation and criminal deterrence. In Bernasco, W, Elffers, H., \& van Gelder, J. L. (Eds.), Oxford Handbook of Offender Decision Making. New York: Oxford University Press. (in press)

Menard, S., \& Elliott, D. S. (1994). Delinquent bonding, moral beliefs, and illegal behavior: A three-wave panel model. Justice Quarterly, 11, 173-188.

Mittal, C., Griskevicius, V., Simpson, J. A., Sung, S., \& Young, E. S. (2015). Cognitive adaptations to stressful environments: When childhood adversity enhances adult executive function. Journal of Personality and Social Psychology, 109, 604-621.

Modecki, K. L. (2008). Addressing gaps in the maturity of judgment literature: Age differences and delinquency. Law and Human Behavior, 32, 78-91.

Molinuevo, B., Pardo, Y., and Torrubia, R. (2011). Psychometric analysis of the Catalan version of the Alabama Parenting Questionaire (APQ) in a community sample. The Spanish Journal of Psychology, 14, 944-955.

Murray, J., Farrington, D. P. \& Eisner, M. P. (2009). Drawing conclusions about causes from systematic reviews of risk factors: The Cambridge Quality Checklists. Journal of Experimental Criminology, 5, 1-23. 
Muthén, L. K., \& Muthén, B. O. (1998-2015). Mplus User's Guide: Statistical Analysis with Latent Variables: User's Guide. Seventh Edition. Los Angeles: Muthén and Muthén. Nagin, D. S., \& Pogarsky, G. (2001). Integrating celerity, impulsivity, and extralegal sanction threats into a model of general deterrence: Theory and evidence. Criminology, 39, 865-892.

Nagin, D. S., \& Pogarsky, G. (2004). Time and punishment: Delayed consequences and criminal behavior. Journal of Quantitative Criminology, 20, 295-317.

Patterson, G. R. (1982). Coercive Family Process. Eugene: Castalia.

Ribeaud, D., \& Eisner, M. P. (2006). The drug-crime link from a self-control perspective: An empirical test in a Swiss youth sample. European Journal of Criminology, 3, 33-67.

Ross, L. T., \& Hill, E. M. (2002). Childhood unpredictability, schemas for unpredictability, and risk taking. Social Behavior and Personality: An International Journal, 30, 453-473.

Sangawi, H. S., Adams, J., \& Reissland, N. (2015). The effects of parenting styles on behavioral problems in primary school children: A cross-cultural review. Asian Social Science, $11,171-186$

Sharma, L., Markon, K. E., \& Clark, L. A. (2014). Toward a theory of distinct types of "impulsive" behaviors: A meta-analysis of self-report and behavioral measures. Psychological Bulletin, 140, 374-408.

Shelton, K. K., Frick, P. J., \& Wootton, J. (1996). Assessment of parenting practices in families of elementary school-age children. Journal of Clinical Child Psychology, 25, 317-329.

Simons, R. L., Simons, L. G., Chen, Y. F., Brody, G. H., \& Lin, K. H. (2007). Identifying the psychological factors that mediate the association between parenting practices and delinquency. Criminology, 45, 481-517. 
Simons-Morton, B. G., Farhat, T., Ter Bogt, T. F., Hublet, A., Kuntsche, E., Gabhainn, S. N., et al. (2009). Gender specific trends in alcohol use: cross-cultural comparisons from 1998 to 2006 in 24 countries and regions. International Journal of Public Health, 54, 199-208.

Simpson, J. A., Griskevicius, V., Kuo, S. I., Sung, S., \& Collins, W. A. (2012). Evolution, stress, and sensitive periods: the influence of unpredictability in early versus late childhood on sex and risky behavior. Evolution, stress, and sensitive periods: the influence of unpredictability in early versus late childhood on sex and risky behavior. Developmental Psychology, 48, 674-686.

Steinberg, L. (2008). A social neuroscience perspective on adolescent risk-taking. Developmental Review, 28, 78-106.

Steinberg, L., Graham, S., O’Brien, L., Woolard, J., Cauffman, E., \& Banich, M. (2009). Age differences in future orientation and delay discounting. Child Development, 80, 28-44.

Sweeten, G. (2012). Scaling criminal offending. Journal of Quantitative Criminology, 28, 533557.

Topçuoğlu, T., Eisner, M. P., \& Ribeaud, D. (2014). Sex Differences in the Effects of Parents' Use of Corporal Punishment on Children's Aggressive Behavior. Annales de la Faculté de Droit d'Istanbul, 46, 185-218.

Tremblay, R. E., Loeber, R., Gagnon, C., Charlebois, P., Larivee, S., \& LeBlanc, M. (1991). Disruptive boys with stable and unstable high fighting behavior patterns during junior elementary school. Journal of Abnormal Child Psychology, 19, 285-300.

Van Gelder, J. L. (2013). Beyond rational choice: The hot/cool perspective of criminal decision making. Psychology, Crime and Law, 19, 745-763

Van Gelder, J. L., Hershfield, H. E., \& Nordgren, L. F. (2013). Vividness of the future self predicts delinquency. Psychological Science, 24, 974-980. 
Van Gelder, J. L., Luciano, E. C., Weulen Kranenbarg, M., \& Hershfield, H. E. (2015).

Friends with my future self: A longitudinal vividness intervention reduces delinquency. Criminology, 53, 158-179.

Vazsonyi, A. T., Mikuška, J., \& Kelley, E. L. (2017). It's time: A meta-analysis on the selfcontrol-deviance link. Journal of Criminal Justice, 48, 48-63.

West, D. J., \& Farrington, D. P. (1973). Who becomes delinquent? Second report of the Cambridge Study in Delinquent Development. London, Heinemann.

Wetzels, P., Enzmann, D., Mecklenburg, E. \& Pfeiffer, C. (2001). Jugend und Gewalt. Eine repräsentative Dunkelfeldanalyse in München und acht anderen deutschen Städten. [Youth and violence. A representative dark number study in Munich and eight other German cities]. Baden-Baden: Nomos.

Wilson, M., \& Daly, M. (1997). Life expectancy, economic inequality, homicide, and reproductive timing in Chicago neighbourhoods. British Medical Journal, 314, 12711274 
Table 1. Correlations Among Corporal Punishment, Inconsistent Punishment, Low Future Orientation, Impulsivity, Volatile Temper and Delinquency $(N=1,197)$.

\begin{tabular}{|c|c|c|c|c|c|c|c|c|}
\hline Variables & 1 & 2 & 3 & 4 & 5 & 6 & $\mathbf{M}$ & SD \\
\hline 1. W6 Corporal punishment & - & - & - & - & - & - & 1.15 & .34 \\
\hline 2. W6 Inconsistent punishment & -.009 & - & - & - & - & - & 2.30 & .70 \\
\hline 3. W6 Future orientation & $-.064 *$ & -.033 & - & - & - & - & 3.17 & .61 \\
\hline 4. W6 Impulsivity & $.104 * *$ & $.110 * *$ & $-.208 * *$ & - & - & - & 2.37 & .56 \\
\hline 5. W6 Volatile temper & $.212 * *$ & $.153 * *$ & $-.108 * *$ & $.264 * *$ & - & - & 1.79 & .64 \\
\hline 6.W7 Delinquency & $.089 * *$ & $.075^{* *}$ & $-.183 * *$ & $.165^{* *}$ & $.092 * *$ & - & 1.03 & 1.65 \\
\hline
\end{tabular}

\section{Control variables}

\begin{tabular}{lcccccccc} 
W5 Corporal punishment & $.410^{* *}$ & -.006 & -.008 & .045 & $.107 * *$ & $.100 * *$ & 1.17 & .37 \\
W5 Inconsistent punishment & -.002 & $.392^{* *}$ & $-.055 \dagger$ & $.100^{* *}$ & $.132^{* *}$ & $.089 * *$ & 2.25 & .67 \\
W5 Future orientation & $-.060^{*}$ & .000 & $.449 * *$ & $-.134 * *$ & $-.103 * *$ & $-.182^{* *}$ & 3.23 & .61 \\
\hline
\end{tabular}




\begin{tabular}{lcccccccc}
\hline W5 Impulsivity & .034 & $.076^{* *}$ & $-.133^{* *}$ & $.308^{* *}$ & $.162^{* *}$ & $.187 * *$ & 2.30 & .62 \\
W5 Volatile temper & $.129 * *$ & $.108^{* *}$ & -.034 & $.172^{* *}$ & $.457 * *$ & $.108^{* *}$ & 1.78 & .64 \\
W5 Delinquency & $.085^{* *}$ & $.115^{* *}$ & $-.131^{* *}$ & $.140^{* *}$ & $.139 * *$ & $.427 * *$ & .98 & 1.73 \\
Gender & .007 & $.090^{* *}$ & $.101^{* *}$ & -.024 & $.102 * *$ & $-.276^{* *}$ & 1.50 & .50 \\
Two non-Swiss parents & $.138^{* *}$ & $.051 \dagger$ & $.124 * *$ & .003 & $.132^{* *}$ & -.043 & .48 & .50 \\
SES & $-.125^{* *}$ & -.044 & $-.102 * *$ & -.005 & $-.133^{* *}$ & $.059 \dagger$ & 46.71 & 19.44 \\
\hline
\end{tabular}

Note. $\mathrm{M}=$ mean; $\mathrm{SD}=$ standard deviation.

$\dagger p<.10 ; * p<.05 ; * * p<.01$ (two-tailed). 
Table 2. Mediation Effects of Harsh and Inconsistent Parental Discipline Practices on Delinquency by Low Future Orientation and Impulsivity $(\mathrm{N}=1,197)$.

$B \quad(\mathrm{SE}) \quad$ STD

Effect on W6 Future orientation

W6 Corporal punishment

$-0.097 \dagger \quad 0.050 \quad-0.054$

W6 Inconsistent punishment

$\begin{array}{lll}-0.039 & 0.024 & -0.045\end{array}$

Sex

$0.080 * \quad 0.032 \quad 0.066$

Non Swiss

$0.083 * \quad 0.035 \quad 0.068$

SES

$-0.002 \dagger \quad 0.001 \quad-0.060$

W5 Future orientation

$0.435 * * \quad 0.029 \quad 0.434$

Effect on W6 Impulsivity

W6 Corporal punishment

$0.159 * * \quad 0.048 \quad 0.096$

W6 Inconsistent punishment

$0.071^{* *} \quad 0.024 \quad 0.089$

Sex

$\begin{array}{lll}-0.034 & 0.032 & -0.030\end{array}$

Non Swiss

$\begin{array}{lll}-0.002 & 0.034 & -0.002\end{array}$

SES

$\begin{array}{lll}0.000 & 0.001 & -0.004\end{array}$

W5 impulsivity

$\begin{array}{lll}0.273^{* *} & 0.029 & 0.299\end{array}$

Effects on W7 Delinquency

W6 Future orientation

$\begin{array}{lll}-0.232 * * & 0.063 & -0.245\end{array}$

W6 Impulsivity

$0.256^{* *} \quad 0.085 \quad 0.250$

W6 Corporal punishment

$\begin{array}{lll}0.305^{* *} & 0.119 & 0.180\end{array}$

W6 Inconsistent punishment

$0.118 \dagger \quad 0.065 \quad 0.144$

Sex

$\begin{array}{lll}-0.680 * * & 0.094 & -0.591\end{array}$

Non Swiss

$\begin{array}{lll}-0.056 & 0.094 & -0.049\end{array}$ 


\begin{tabular}{llll}
\hline SES & $0.005^{*}$ & 0.002 & 0.167 \\
W5 Delinquency & $0.207^{* *}$ & 0.023 & 0.623 \\
Indirect effects & & & \\
W6 Corporal punishment -> W6 Future & $0.023 \dagger$ & 0.013 & n.a. \\
orientation -> W7 Delinquency & & & \\
W6 Inconsistent punishment -> W6 Future & 0.009 & 0.006 & n.a. \\
orientation -> W7 Delinquency & & & \\
W6 Corporal punishment -> W6 Impulsivity -> & $0.041^{*}$ & 0.018 & n.a. \\
W7 Delinquency & & & \\
W6 Inconsistent punishment -> W6 Impulsivity & $0.018^{*}$ & 0.009 & n.a. \\
-> W7 Delinquency
\end{tabular}

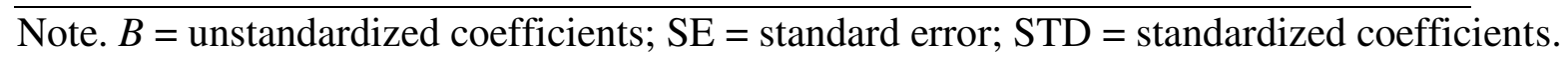
$\dagger p<0.10 ; * p<0.05 ; * * p<0.01$ (two-tailed). 
Table 3a. Robustness Checks of Path Analyses of Delinquency on Harsh and Inconsistent Parental Discipline Practices and Shortsightedness (N = 1,197)

Model 1: Volatile Model 2: Violence Model 3: Theft

\section{Temper}

Effects

B

$(\mathrm{SE})$

B

(SE)

B

(SE)

Effect on W6 future orientation

$\begin{array}{lcccccc}\text { W6 Corporal punishment } & -0.097 \dagger & 0.050 & -0.098 \dagger & 0.050 & -0.09)^{\dagger} & 0.050 \\ \text { W6 Inconsistent punishment } & -0.039 & 0.024 & -0.039 & 0.024 & -0.039 & 0.024 \\ \text { Sex } & 0.081^{*} & 0.032 & 0.081^{*} & 0.032 & 0.081^{*} & 0.032 \\ \text { Non Swiss } & 0.083^{*} & 0.035 & 0.083^{*} & 0.035 & 0.083^{*} & 0.035 \\ \text { SES } & -0.002^{\dagger} & 0.001 & -0.002^{\dagger} & 0.001 & -0.002^{\dagger} & 0.001 \\ \text { W5 Future orientation } & 0.435^{* *} & 0.029 & 0.435^{* *} & 0.029 & 0.435^{* *} & 0.029 \\ \text { Effect on W6 impulsivity } & & & & & & \\ \text { W6 Corporal punishment } & 0.158^{* *} & 0.048 & 0.159^{* *} & 0.048 & 0.158^{* *} & 0.048 \\ \text { W6 Inconsistent punishment } & 0.071^{* *} & 0.024 & 0.071^{* *} & 0.024 & 0.071^{* *} & 0.024\end{array}$




\begin{tabular}{|c|c|c|c|c|c|c|}
\hline Sex & -0.034 & 0.032 & -0.034 & 0.032 & -0.034 & 0.032 \\
\hline Non Swiss & -0.002 & 0.034 & -0.002 & 0.034 & -0.002 & 0.034 \\
\hline SES & 0.000 & 0.001 & 0.000 & 0.001 & 0.000 & 0.001 \\
\hline W5 Impulsivity & $0.273 * *$ & 0.029 & $0.273 * *$ & 0.029 & $0.273 * *$ & 0.029 \\
\hline \multicolumn{7}{|l|}{ Effect on W6 Volatile temper } \\
\hline W6 Corporal punishment & $0.270 * *$ & 0.053 & - & - & - & - \\
\hline W6 Inconsistent punishment & $0.086^{* *}$ & 0.024 & - & - & - & - \\
\hline Sex & $0.097 * *$ & 0.032 & - & - & - & - \\
\hline Non Swiss & $0.070 *$ & 0.036 & - & - & - & - \\
\hline SES & $-0.002 \uparrow$ & 0.001 & - & - & - & - \\
\hline W5 Volatile temper & $0.413^{* *}$ & 0.028 & - & - & - & - \\
\hline \multicolumn{7}{|l|}{ Effects on W7 Delinquency } \\
\hline W6 Future orientation & $-0.226 * *$ & 0.063 & $-0.423 * *$ & 0.148 & $-0.195 *$ & 0.082 \\
\hline W6 Impulsivity & $0.237 * *$ & 0.085 & $0.703 * *$ & 0.177 & $0.242 *$ & 0.100 \\
\hline
\end{tabular}




\begin{tabular}{|c|c|c|c|c|c|c|}
\hline W6 Volatile temper & 0.081 & 0.071 & - & - & - & - \\
\hline W6 Corporal punishment & $0.281 *$ & 0.118 & 0.162 & 0.227 & $0.421 * *$ & 0.141 \\
\hline W6 Inconsistent punishment & $0.110 \dagger$ & 0.067 & -0.010 & 0.151 & $0.182 *$ & 0.080 \\
\hline Sex & $-0.696 * *$ & 0.094 & $-1.407 * *$ & 0.298 & $-0.728 * *$ & 0.114 \\
\hline Non Swiss & -0.065 & 0.095 & 0.179 & 0.246 & -0.182 & 0.124 \\
\hline SES & $0.005^{*}$ & 0.002 & -0.001 & 0.006 & $0.005 \dagger$ & 0.003 \\
\hline W5 Delinquency & $0.204 * *$ & 0.023 & $0.577 * *$ & 0.141 & $0.295 * *$ & 0.047 \\
\hline \multicolumn{7}{|l|}{ Indirect effects } \\
\hline Corporal punishment $->$ future & $0.022 \dagger$ & 0.013 & 0.041 & 0.026 & 0.019 & 0.013 \\
\hline \multicolumn{7}{|l|}{ orientation -> delinquency } \\
\hline Inconsistent punishment $->$ future & 0.009 & 0.006 & 0.016 & 0.012 & 0.008 & 0.006 \\
\hline \multicolumn{7}{|l|}{ orientation -> delinquency } \\
\hline Corporal punishment -> impulsivity -> & $0.038 *$ & 0.018 & $0.112 *$ & 0.045 & $0.038 \dagger$ & 0.020 \\
\hline
\end{tabular}

delinquency 


$\begin{array}{lllllll}\text { Inconsistent punishment -> impulsivity } & 0.017 * & 0.008 & 0.050^{*} & 0.021 & 0.017 \dagger & 0.009 \\ \text {-> delinquency } & & & & & - & - \\ \text { Corporal punishment -> volatile temper } & 0.022 & 0.020 & - & - & \\ \text {-> delinquency } & & & & & - & -\end{array}$

temper $\rightarrow$ delinquency

Note. $B=$ unstandardized coefficients; $\mathrm{SE}=$ standard error. Delinquency was measured as violence and theft respectively for models 2 and 3.

$\dagger p<0.10 ; * p<0.05 ; * * p<0.01$ (two-tailed). 
Table 3b. Robustness Checks of Path Analyses of Delinquency on Harsh and Inconsistent Parental Discipline Practices and Shortsightedness $(\mathrm{N}=1,197)$

Model 4: Longer-term relations

Effects

B

(SE)

Effect on W6 Future orientation

W5 Corporal punishment

$-0.017$

0.058

W5 Inconsistent punishment

$-0.058^{*}$

0.029

Sex

$0.120 * *$

0.035

Non Swiss

$0.124 * *$

0.039

SES

$-0.002$

0.001

W4 Impulsivity

$-0.050 \dagger$

0.030

Effect on W6 impulsivity

W5 Corporal punishment

0.063

0.047

W5 Inconsistent punishment

$0.080 * *$

Sex

$-0.025$

0.033

Non Swiss

0.003

0.036

SES

0.000

0.001

W4 Impulsivity

$0.126^{* *}$

0.028

Effects on W7 Delinquency

W6 Future orientation

$-0.246^{* *}$

0.065

W6 Impulsivity

$0.342 * *$

0.084

W5 Corporal punishment

$0.253 * *$

0.097

W5 Inconsistent punishment

$0.180 * *$

0.067 
Sex

$-0.828 * *$

0.096

Non Swiss

$-0.096$

0.095

SES

0.003

0.002

W4 Delinquency

$0.221 * *$

0.047

Indirect effects

Corporal punishment $->$ future

0.004

0.014

orientation -> delinquency

Inconsistent punishment -> future

$0.014 \dagger$

0.008

orientation -> delinquency

Corporal punishment -> impulsivity ->

0.022

0.017

delinquency

Inconsistent punishment -> impulsivity

$0.027 * *$

0.010

-> delinquency

Note. $B=$ unstandardized coefficients; $\mathrm{SE}=$ standard error.

$\dagger p<0.10 ; * p<0.05 ; * * p<0.01$ (two-tailed). 


\section{Figure 1}

Hypothesized Relations between Corporal Punishment, Inconsistent Punishment, Future School Orientation, Impulsivity and Delinquency

Parenting

Present-orientation

Outcome

Practice

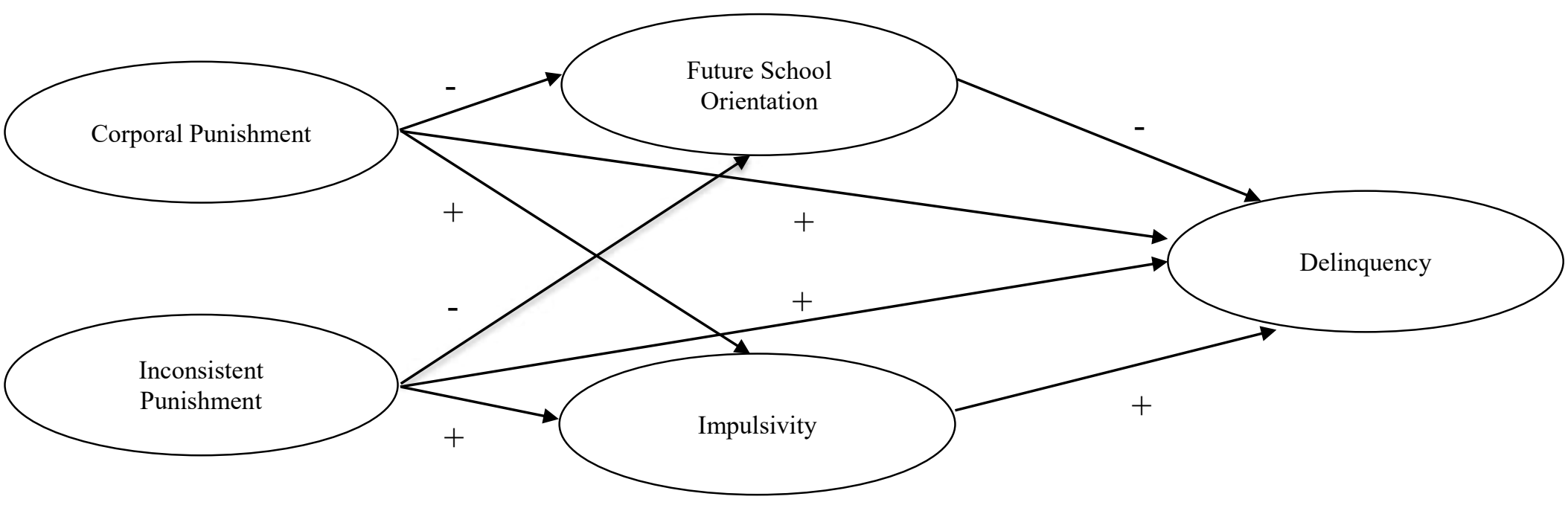

Note. '+' and '-' denote positive and negative relations respective 
